\title{
THE BLOOD-TENDON BARRIER: IDENTIFICATION AND CHARACTERISATION OF A NOVEL TISSUE BARRIER IN TENDON BLOOD VESSELS
}

\author{
C. Lehner ${ }^{1,4 *}$, R. Gehwolf ${ }^{1}$, J.C. Ek ${ }^{2}$, S. Korntner ${ }^{1}$, H. Bauer ${ }^{3}$, H-C. Bauer ${ }^{1,4}$, A. Traweger ${ }^{1}$ and H. Tempfer ${ }^{1}$ \\ ${ }^{1}$ Institute of Tendon and Bone Regeneration, Paracelsus Medical University, SCI-TReCS, Salzburg, Austria \\ ${ }^{2}$ Institute for Neuroscience and Physiology, Department of Physiology, Sahlgrenska Academy, \\ University of Gothenburg, Gothenburg, Sweden \\ ${ }^{3}$ Department of Ecology and Evolution, University of Salzburg, Salzburg, Austria \\ ${ }^{4}$ University Clinic for Trauma Surgery and Sports Injuries, Salzburg, Austria
}

\begin{abstract}
Tissue barriers function as "gate keepers" between different compartments (usually blood and tissue) and are formed by specialised membrane-associated proteins, localising to the apicolateral plasma membrane domain of epithelial and endothelial cells. By sealing the paracellular space, the free diffusion of solutes and molecules across epithelia and endothelia is impeded. Thereby, tissue barriers contribute to the establishment and maintenance of a distinct internal and external environment, which is crucial during organ development and allows maintenance of an organspecific homeostatic milieu. So far, various epithelial and endothelial tissue barriers have been described, including the blood-brain barrier, the blood-retina barrier, the blood-testis barrier, the blood-placenta barrier, and the cerebrospinal fluid (CSF)-brain barrier, which are vital for physiological function and any disturbance of these barriers can result in severe organ damage or even death. Here, we describe the identification of a novel barrier, located in the vascular bed of tendons, which we term the bloodtendon barrier (BTB). By using immunohistochemistry, transmission electron microscopy, and tracer studies we demonstrate the presence of a functional endothelial barrier within tendons restricting the passage of large blood-borne molecules into the surrounding tendon tissue. We further provide in vitro evidence that the BTB potentially contributes to the creation of a distinct internal tissue environment impacting upon the proliferation and differentiation of tendon-resident cells, effects which might be fundamental for the onset of tendon pathologies.
\end{abstract}

Keywords: Tendon vasculature, blood vessels, endothelial cells, barrier, tight junctions, tracer, vascular permeability, serum, tendinopathy.

*Address for correspondence:

Christine Lehner, PhD

Institute of Tendon and Bone Regeneration

Paracelsus Medical University - Spinal Cord Injury \& Tissue Regeneration Center Salzburg

A-5020 Salzburg, Austria

Telephone Number: +43 662 2420-80867

E-mail: Christine.lehner@pmu.ac.at

\section{Introduction}

Tendons harbour a population of multipotent stem/ progenitor cells, which are heterogeneous and could be identified in both peritendon and tendon proper. These cells are described to reside both in the vascular compartment and the tendon proper (Lui, 2013; Tempfer et al., 2009). The niche of these cells is not yet fully understood. The finely tuned molecular and cellular composition of this niche appears to be crucial for stem cell differentiation and maintenance (Bi et al., 2007; Katenkamp et al., 1976; Tempfer et al., 2009; Zhang and Wang, 2013; Zhang et al., $2010 \mathrm{~b}$ ). So far, besides oxygen tension and mechanical stimuli, few other niche-determining factors are known including the composition and nano-/micro-structure of the extracellular matrix (ECM) (Bi et al., 2007; Rui et al., 2011b; Tong et al., 2012; Wang et al., 2008; Zhang and Wang, 2013).

The internal milieu of the niche is severely changed during tissue degeneration, trauma and injury, often resulting in pathological alterations such as hyperproliferation, erroneous tendon cell differentiation, and calcification (Oliva et al., 2012; Rui et al., 2011a). Therefore, it appears reasonable to suggest that rapid restoration and stabilisation of the niche following an injury is paramount in initiating and supporting the healing process.

Healthy tendons are sparsely vascularised (Ahmed et al., 1998; Hooper et al., 1984; Weidman et al., 1984; Zhang et al., 1990), particularly sheathed tendons - such as the flexor tendon of the hand - and depend on synovial fluid diffusion to provide nutrition (Hagberg et al., 1992; Jones et al., 2003; Lundborg et al., 1980; Manske and Lesker, 1985; Tempfer and Traweger, 2015). Between densely packed collagen fibre bundles continuous rows of tenocytes are found perfectly aligned with the collagen structure in direction of the strain (Kannus, 2000; Legerlotz et al., 2014), exhibiting an exceptionally low turnover rate, which may also account for the poor regenerative capacity of tendon tissue (Heinemeier et al., 2013). In contrast, chronically inflamed tendons or tendons which are recovering from injury are characterised by hypercellularity and hypervascularity, due to increased proliferation of tenocytes and vascular cells (Andersson et al., 2011; Astrom and Rausing, 1995). In vitro, an increase in proliferation has been observed in isolated tendon cells when cultivated with serum or platelet rich plasma (Mazzocca et al., 2012; Wang et al., 2012). 
So far, tendon vasculature has been investigated in the context of tendon development, tendinopathies and vascularisation of tendon tissue grafts (Fenwick et al., 2002). Little attention has been paid to the tendon vasculature as a restrictive system impeding the passive transport of solutes and molecules across vessel walls and thereby controlling the homeostasis of the tendon-specific niche. Such influx and efflux control systems usually rely on a sophisticated network of membrane-spanning proteins (e.g. occludin, claudins and junctional adhesion molecules) linked to a vast array of cytoplasmic proteins, which seal the paracellular space between neighbouring cells (Bauer et al., 2014; Bauer et al., 2011).

The aim of this study was to investigate the structural, functional and molecular characteristics of blood vessels in human and mouse tendon tissue. By means of transmission electron microscopy (TEM), RT-PCR, immunohistochemistry, and in vivo tracer studies we showed that the vascular lining of tendon vessels serves as a size-selective diffusion restraint, reminiscent of the tissue barrier located in the cerebral microvasculature of vertebrates (Abbott et al., 2010). Moreover, we cultivated tendon-derived cells with increasing serum concentrations, thus mimicking a barrier breakdown in vitro, and examined the effect on proliferation and differentiation.

We propose that this blood-tendon barrier (BTB) is imperative for the establishment of stable homeostatic conditions, thus potentially contributing to the regulation of tendon cell differentiation.

\section{Materials and Methods}

\section{Sample collection}

In total, 14 human tendon samples (biceps tendons: $n=9,8$ men, 1 woman; mean age 60.4 years, range 30 to 75 , obtained from rotator cuff repairs; semitendinosus tendons: $n=3,2$ men, 1 woman; mean age 31.6 years, range 18 to 55 , obtained from anterior cruciate ligament reconstruction; and Palmaris longus tendons: $n=2,1$ man, 1 woman; mean age 56 years, range 37 to 75 ) were obtained with patients' informed consents as approved by the Salzburg ethics committee (approval \#E-Nr. 1809).

15 female C57BL/6 mice (twelve months old) were provided by Charles River Laboratories (Sulzfeld, Germany). Care of the animals and all animal experiments have been conducted according to national and international guidelines and were approved by the local ethics committee.

\section{Cell culture}

Freshly obtained biopsy specimens from human biceps $(n=7,6$ male, 1 female $)$ and semitendinosus $(n=3,2$ male, 1 female) tendons were cut into small pieces under sterile conditions followed by a $12 \mathrm{~h}$ digestion step in Minimum Essential Medium (MEM), supplemented with $15 \mathrm{mg} /$ $\mathrm{mL}$ collagenase II (Gibco, Invitrogen, Lofer, Austria) at $37{ }^{\circ} \mathrm{C}, 85 \%$ humidity and $5 \% \mathrm{CO}_{2}$. Incubated in MEM supplemented with $10 \%$ foetal bovine serum (FBS) the resulting cell suspension gave rise to an adherent culture of tendon-derived cells (TDCs), which was passaged once before the experiments were performed.

\section{Proliferation assay}

To examine the effect of serum on cell proliferation, human TDCs were cultured in the presence of pooled human serum (Sigma, Vienna, Austria, \#H6914) at concentrations of $10 \%, 5 \%, 1 \%$ and without serum. Cells were counted after 3 and $5 \mathrm{~d}$. For an additional experiment, we cultured human tendon cells either with $10 \%$ serum or without serum. Cells cultured without serum were supplemented with serum on the eighth day. In parallel, serum was withdrawn from cells cultured with serum so far. Again, cell numbers were counted every second or third day until cells reached confluence after two weeks.

\section{Differentiation experiments}

To assess the effect of serum on tendon cell differentiation potential, human TDCs were cultured with and without serum supplementation for one week. After this period, either Adipolife ${ }^{\mathrm{TM}}$, Chondrolife ${ }^{\mathrm{TM}}$ or Osteolife ${ }^{\mathrm{TM}}$ (LM0023, Lifeline Cell Technology, Frederick, MD, USA), serum-free adipogenic, chondrogenic or osteogenic media, respectively, were added to both cell types for two weeks. Subsequently, 1) adipogenic differentiation was assessed by Oil red $\mathrm{O}$ staining and quantitative RT-PCR (qRTPCR) determining the expression level of peroxisome proliferator-activated receptor gamma (PPAR $\gamma$ ), a regulator of adipocyte differentiation (Rosen and Spiegelman, 2001), 2) chondrogenic differentiation by Alcian blue, collagen II and aggrecan staining, 3) osteogenic differentiation by staining for alkaline phosphatase, qPCR on three osteogenesis markers (runt-related transcription factor 2, RUNX2; bone sialoprotein 1, BSP1; and parathyroid hormone 1 receptor, PTH1R) and visualisation of calcium deposits by Alizarin S (Sigma, Vienna, Austria) staining.

\section{ß-Galactosidase staining}

In order to exclude that lack of serum affects cell senescence, we performed a $ß$-galactosidase staining according to the protocol described by Dimri et al. (1995). To this end, cells were cultivated for 2 weeks with either Adipolife ${ }^{\mathrm{TM}}$ without serum, Adipolife ${ }^{\mathrm{TM}}$ with $10 \%$ human serum, MEM with human serum, Osteolife ${ }^{\mathrm{TM}}$ without serum or Osteolife ${ }^{\mathrm{TM}}$ with $10 \%$ human serum. The cells were fixed for 1 min with $3 \%$ paraformaldehyde (PFA) at room temperature and subsequently washed 3 times with cold phosphate-buffered saline (PBS). The cells were then incubated at $37^{\circ} \mathrm{C}$ for $8 \mathrm{~h}$ with a buffer containing $40 \mathrm{mM}$ citric acid, $5 \mathrm{mM}$ potassium ferrocyanide, $5 \mathrm{mM}$ potassium ferricyanide, $150 \mathrm{mM} \mathrm{NaCl}, 2 \mathrm{mM} \mathrm{MgCl}$ and freshly added X-Gal $(1 \mathrm{mg} / \mathrm{mL})$ at $\mathrm{pH} 6$. After the cells were mounted with cover slips, they were microscopically analysed.

\section{Alizarin S staining and quantification}

In order to visualise and quantitate the amount of calcification, cells cultured in 6-well plates were fixed in $4 \%$ PFA for $20 \mathrm{~min}$ at room temperature and stained with a solution of $0.1 \%$ Alizarin $\mathrm{S}$ at $\mathrm{pH} 4.5$ for $5 \mathrm{~min}$ at room temperature. After 3 washing steps in double-distilled $\mathrm{H}_{2} \mathrm{O}$ to remove any unbound stain, the bound stain was dissolved by using $800 \mu \mathrm{L}$ of $10 \%$ (v/v) acetic acid under gentle agitation for $30 \mathrm{~min}$. After vortexing for $30 \mathrm{~s}$, the 
tubes were heated to $85^{\circ} \mathrm{C}$ for $10 \mathrm{~min}$ and then centrifuged at $15000 \times \mathrm{g}$ for $10 \mathrm{~min}$. $500 \mu \mathrm{L}$ of the supernatant was removed and transferred to new $1.5 \mathrm{~mL}$ micro-centrifuge tubes and $200 \mu \mathrm{L}$ of ammonium hydroxide solution $10 \%$ ( $\mathrm{v} / \mathrm{v})$ was added to achieve a $\mathrm{pH}$ of between 4.1-4.5. Aliquots $(150 \mu \mathrm{L})$ of each sample were read in triplicate at an absorbance of $405 \mathrm{~nm}$ on a microplate reader (Tristar LB 941, Berthold Technologies, Bad Wildbad, Germany). In order to correct for varying cell numbers under different conditions, OD values were normalised to DNA content, which was determined in parallel cultures.

\section{Oil red $O$ staining and quantification}

To determine the extent of adipogenic differentiation, cells cultured in 6-well plates were fixed in $4 \%$ PFA for $20 \mathrm{~min}$ at room temperature and stained with Oil red $\mathrm{O}$ working solution for $15 \mathrm{~min}$ at room temperature. After 3 washing steps, bound Oil red O was dissolved in $400 \mu \mathrm{L}$ isopropanol and absorbance was measured at a wavelength of $540 \mathrm{~nm}$ (Tristar LB 941, Berthold Technologies). In order to correct for varying cell numbers under different conditions, OD values were normalised to DNA content, which was determined in parallel cultures.

\section{DNA quantification}

Cells were lysed in $5 \mathrm{mM}$ Tris- $\mathrm{HCl}(\mathrm{pH} \mathrm{8.0)}$ ) by 3 freeze/ thaw cycles, followed by sonication for $20 \mathrm{~min}$. DNA was measured in the supernatant of the solutions using a fluorescent Quant-iT ${ }^{\mathrm{TM}}$ PicoGreen ${ }^{\circledR}$ dsDNA reagent assay kit (Invitrogen, Carlsbad, CA,USA, \# P7589) according to the manufacturer's instructions.

\section{Tracer injection}

To assess the tightness of tendon blood vessels, mice (C57BL/6) were injected with $0.10-0.15 \mathrm{mg} / \mathrm{g}$ of $10 \mathrm{kD}$ biotin-dextran (BDA) per animal (Molecular Probes; Carlsbad, CA, USA, \#D-1956) or a 287 D biotinylated Neurobiotin ${ }^{\mathrm{TM}}$ tracer (Vector Laboratories, Peterborough, UK, \#SP-1120) into the tail vein. The tracer was allowed to circulate for $15 \mathrm{~min}$ before the animals were euthanised by an overdose of sodium thiopental (Abcur, Helsingborg, Sweden $)(0.4 \mathrm{~g} / \mathrm{kg}$ animal $)$ through an IP injection. Achilles tendons were removed, cut into $1 \mathrm{~mm}^{3}$ cubes, immersionfixed in $4 \%$ PFA at $4{ }^{\circ} \mathrm{C}$ overnight, thoroughly washed in PBS and further processed for paraffin embedding. Heart and brain tissue as controls were processed in parallel.

\section{Immunohistochemistry}

To identify the presence of tight junction proteins in tendon blood vessels, human tendon biopsy samples (Palmaris longus, biceps tendon) were fixed in $4 \%$ PFA in PBS at $4{ }^{\circ} \mathrm{C}$ overnight. Achilles tendons from C57BL/6 mice were perfusion-fixed with $4 \%$ PFA in PBS and immersionfixed in the same fixative at $4{ }^{\circ} \mathrm{C}$ overnight. Tissues were processed for paraffin embedding, sectioned $(6 \mu \mathrm{m})$, and stained with antibodies specific for zonula occludens (ZO-1; Invitrogen, Lofer, Austria \#61-7300), occludin (Invitrogen, \#71-1500), claudin 3 (Abcam, Cambridge, UK, ab15102), and claudin 5 (Abcam, ab53765). Incubation with primary antibodies was performed at $4{ }^{\circ} \mathrm{C}$ overnight. Primary antibody was omitted for negative controls. After treatment with Power Vision polyHRP-antirabbit IgG (ImmunoLogic, Duiven, Netherlands), sections were incubated with 3,3'-diaminobenzidine (DAB) tetrahydrochloride, Sigma Aldrich, Vienna, Austria), and counterstained with Novocastra ${ }^{\mathrm{TM}}$ Haematoxylin dye (Leica Biosystems, Newcastle, UK) and mounted in Eukitt (Sigma Aldrich, Vienna, Austria).

For double-immunolabelling, mouse Achilles tendons were fixed in $4 \%$ PFA, washed with PBS-sucrose and cryosectioned on a Leica CM 1950 microtome. Sections $(15 \mu \mathrm{m})$ were stained with biotinylated Bandeiraea simplicifolia lectin (BSL, obtained from Sigma Aldrich, Vienna, Austria) visualising blood vessels, and antibodies specific for ZO-1, occludin, claudin 3, and claudin 5 . Primary antibodies were visualised with secondary antibodies labelled with Alexa Fluor 568 (donkey anti rabbit Alexa Fluor 568, Life Technologies, Vienna, Austria), BSL was visualised with Streptavidin, Alexa Fluor 488 conjugate (Life Technologies, Vienna, Austria) and analysed on a LSM710 (Zeiss, Munich, Germany).

Tracer-injected, paraffin-embedded Achilles tendons were sectioned $(6 \mu \mathrm{m})$ and mounted on Superfrost ultra plus glass slides (Thermo Scientific, Vienna, Austria). Following deparaffinisation and dehydration, sections were incubated in blocking reagent (Roth, Graz, Austria) for $30 \mathrm{~min}$, incubated with a streptavidin-HRP labelled antibody (Dako, Glostrup, Denmark, \#90397) for $1 \mathrm{~h}$, and developed with DAB after several washing steps in PBS.

\section{Immunocytochemistry}

In order to better characterise the cells used for the in vitro experiments, human TDCs were fixed with $4 \%$ paraformaldehyde, washed with PBS and incubated with antibodies directed against tenomodulin (Santa Cruz, Heidelberg, Germany, sc-98875), pro-collagen1a1 (Abcam, Cambridge, UK, ab64409), CD44, CD29, CD90, CD105, and CD45 (Abcam, Cambridge, UK, ab93758) at $4{ }^{\circ} \mathrm{C}$ for $48 \mathrm{~h}$. Secondary antibodies labelled with Alexa Fluor 568 and cy5 (donkey anti rabbit Alexa Fluor 568 and donkey anti rat cy5, Life Technologies, Vienna, Austria) were used to visualise primary antibodies.

\section{Laser-capture microdissection and RT-PCR}

To specifically analyse tendon blood vessels, laser-capture microdissection was performed on paraffin-embedded tissue sections of mouse Achilles and human biceps tendons. Parts from the vascular bed and the dense collagenous region of the tendon were dissected using a PALM MicroBeam laser capture microscope from Zeiss and captured tissue was placed in an RNase-free PCR cap. Extracted total RNA was directly transcribed into cDNA using the High Capacity RNA-to-cDNA Master Mix (Life Technologies). PCR was performed using the smallest available intron-spanning TaqMan Gene Expression Assay (with amplicons $<100 \mathrm{bp}$, Life Technologies, Vienna, Austria) for occludin (assay ID: Hs00170162 $\mathrm{m} 1$; Mm00500912_m1), claudin 1 (Hs00221623_m1; Mm01342184_m1), claudin 3 (assay ID: Hs00265816_s1; Mm00515499_s1), claudin 4 (assay ID: Mm00515514_s1), claudin 5 (assay ID: Hs01561351_m1; Mm00727012_s1), and claudin 12 (assay ID: Hs00273258_s1; Mm01316509_ 
$\mathrm{m} 1)$. Amplification efficiency of the house-keeping gene hypoxanthine-guanine phosphoribosyltransferase (HPRT, assay ID: Hs01003267_m1; Mm01545399_ml) was used as an internal control. PCR products were separated on an agarose gel and stained with ethidium bromide.

\section{Electron microscopy}

For analysis of tendon blood vessels on the ultrastructural level, 3 mouse Achilles tendons were perfusion-fixed with $2 \%$ glutaraldehyde in PBS and immersion-fixed in $2 \%$ glutaraldehyde in $100 \mathrm{mM}$ phosphate buffer (PB) (pH 7.0) at $4{ }^{\circ} \mathrm{C}$ overnight. After several washing steps in phosphate buffer specimens were post-fixed in $1 \%$ glutaraldehyde and $1 \%$ osmium tetroxide in $50 \mathrm{mM} \mathrm{PB}$ (pH 6.2) at $4{ }^{\circ} \mathrm{C}$. Following extensive rinsing in distilled water and incubation in $1 \%$ uranyl acetate, tissues were dehydrated in a graded ethanol series and embedded using the Ultra Bed Low Viscosity Epoxy Kit (Electron Microscopy Sciences, Hatfield, PA, USA) according to the manufacturer's instructions.

Semithin sections were cut and stained with Azur II to determine the region of interest. Ultrathin sections ( $80 \mathrm{~nm}$ ) were cut on an ultramicrotome Reichert Ultracut S (Optische Werke C. Reichert, Vienna, Austria), mounted on Formvar-coated copper slit grids and contrast stained with uranyl acetate/lead citrate in an ultrostainer (Leica/ Reichert, Vienna, Austria). All ultrathin sections from the proximal, the middle and the distal part of the tendons were examined in a transmission electron microscope LEO EM 910 (LEO, Elektronenmikroskopie Ltd, Oberkochen, Germany) operating at $80 \mathrm{kV}$.

\section{Quantitative RT-PCR}

To assess the expression levels of genes associated with differentiation into the adipogenic and osteogenic lineages, we performed quantitative RT-PCR. To this end, total RNA from human tendon cultures was isolated using TRI Reagent (Sigma-Aldrich, Vienna, Austria) and reverse-transcribed with iScript Reverse Transcription Supermix for RT-qPCR (BioRad, Munich, Germany, \# 170-8841). Products were amplified using the Taq Man Gene Expression Master Mix (Thermo Fisher Scientific, Applied Biosystems, Vienna, Austria, \# 4369016) and the smallest available PrimeTime qPCR assays from IDT (Integrated DNA Technologies, Coralville, IA, USA) for PPAR $\gamma$ (ID assay: Hs.PT.58.25464465), RUNX2 (ID assay: Hs.PT.56a.19568141), BSP1 (ID assay: Hs.PT.58.20755025), and PTH1R (ID assay: Hs.PT.58.3437800) using a CFX96 Touch $^{\mathrm{TM}}$ Real-Time PCR Detection System (BioRad, Munich, Germany). PCR was performed applying the following temperature regimen: 2 min $50{ }^{\circ} \mathrm{C}$ uracil DNA glycosylase (UDG) incubation; $10 \mathrm{~min} 95^{\circ} \mathrm{C}$ enzyme activation; $15 \mathrm{~s} 95^{\circ} \mathrm{C}, 1 \mathrm{~min}$, $60^{\circ} \mathrm{C}$ for 40 cycles. For normalisation the house-keeping genes hypoxanthine-guanine phosphoribosyltransferase (HPRT1, Hs.PT.39a22214821), ribosomal protein, large, P0 (RPLP0, Hs.PT.56.40434846), and TATA box-binding protein (TBP, Hs.PT.39a.22214825), were used as internal controls. Cq values were analysed using qBasePlus v. 2.4 (Biogazelle NV, Zwijnaarde, Belgium) and normalised relative quantities were calculated by normalising the data to the expression of three previously validated endogenous control genes as described by Vandesompele et al. (2002). The normalised quantities were then determined for the candidate genes scaled against the expression values determined for the undifferentiated control (MEM+HS) to generate fold changes in expression. Measurements from three independent experiments $(n=3)$ are shown (technical replicate for each sample) and expressed as mean \pm standard error of the mean (SEM).

\section{Western blot}

To determine the expression levels of extracellular matrix proteins, lysates from human tendon cells were prepared as described previously (Traweger et al., 2008). Protein contents were quantified by using a BCA protein assay kit (Pierce, Rockford, IL, USA). Equal amounts of protein were subjected to SDS-polyacrylamide gel electrophoresis (PAGE) using a $7.5 \%$ or $10 \%$ gel. After blotting, the polyvinylidene difluoride (PVDF) membrane was incubated in $5 \%$ non-fat milk powder in Tris-buffered saline-Tween (TBS-T). Immunodetection was performed using primary antibodies recognising pro-collagen1a1 of Colla1 (Santa Cruz, Heidelberg, Germany, sc-8782), MMP2 (Abcam, Cambridge, UK, ab37150), MMP9 (Cedarlane, Ontario, Canada), $\beta$-actin (Santa Cruz, sc47778) and secondary HRP-labelled goat anti-rabbit and goat anti-mouse antibodies, respectively (BioRad, Munich, Germany). Bands were visualised using the SuperSignal West Pico Chemiluminescent Substrate from Pierce (Thermo Scientific, Vienna, Austria). All experiments were repeated at least three times. Band intensities were measured densitometrically and normalised to $\beta$-actin expression using the Image Lab Software 5.1 from BioRad.

\section{Zymography}

Matrix metalloproteinase activities were assessed by gelatine zymography in tendon cell cultures. To this end, human TDCs were incubated with increasing serum $(0 \%$, $1 \%, 5 \%$ and $10 \%$ ) concentrations. After $4 \mathrm{~d}$, serumcontaining medium was removed, cells were washed twice with PBS and serum-free medium was added to the cell cultures. After 10 min the supernatant was taken and gelatine zymography was performed as described previously (Krizbai et al., 2000). Briefly, cells were lysed in a buffer containing $20 \mathrm{mM}$ Tris- $\mathrm{HCl}$ (pH 7.5), $150 \mathrm{mM}$ $\mathrm{NaCl}, 1 \%$ Triton X-100, and $0.1 \%$ SDS. Equal amounts of protein were loaded on $7.5 \%$ polyacrylamide gels containing gelatine $(1 \mathrm{mg} / \mathrm{mL})$. Following electrophoresis, the gels were given a 30 min wash with $\mathrm{ddH}_{2} \mathrm{O}$ containing $2.5 \%$ Triton $\mathrm{X}-100$, and then incubated with a substrate buffer (50 mM Tris- $\mathrm{HCl}(\mathrm{pH} 8.0)$ containing $5 \mathrm{mM}$ $\mathrm{CaCl}_{2}$ ) overnight at $37^{\circ} \mathrm{C}$. The gels were then stained with Coomassie Blue R-250 for 30 min followed by several washing steps. Band intensities were measured densitometrically using the Image Lab Software 5.1 from Biorad.

\section{Statistical analysis}

Statistical analyses were performed using Graph Pad Prism software (version 5.04). Densitometric data are presented as means with standard deviations. One-way analysis of 


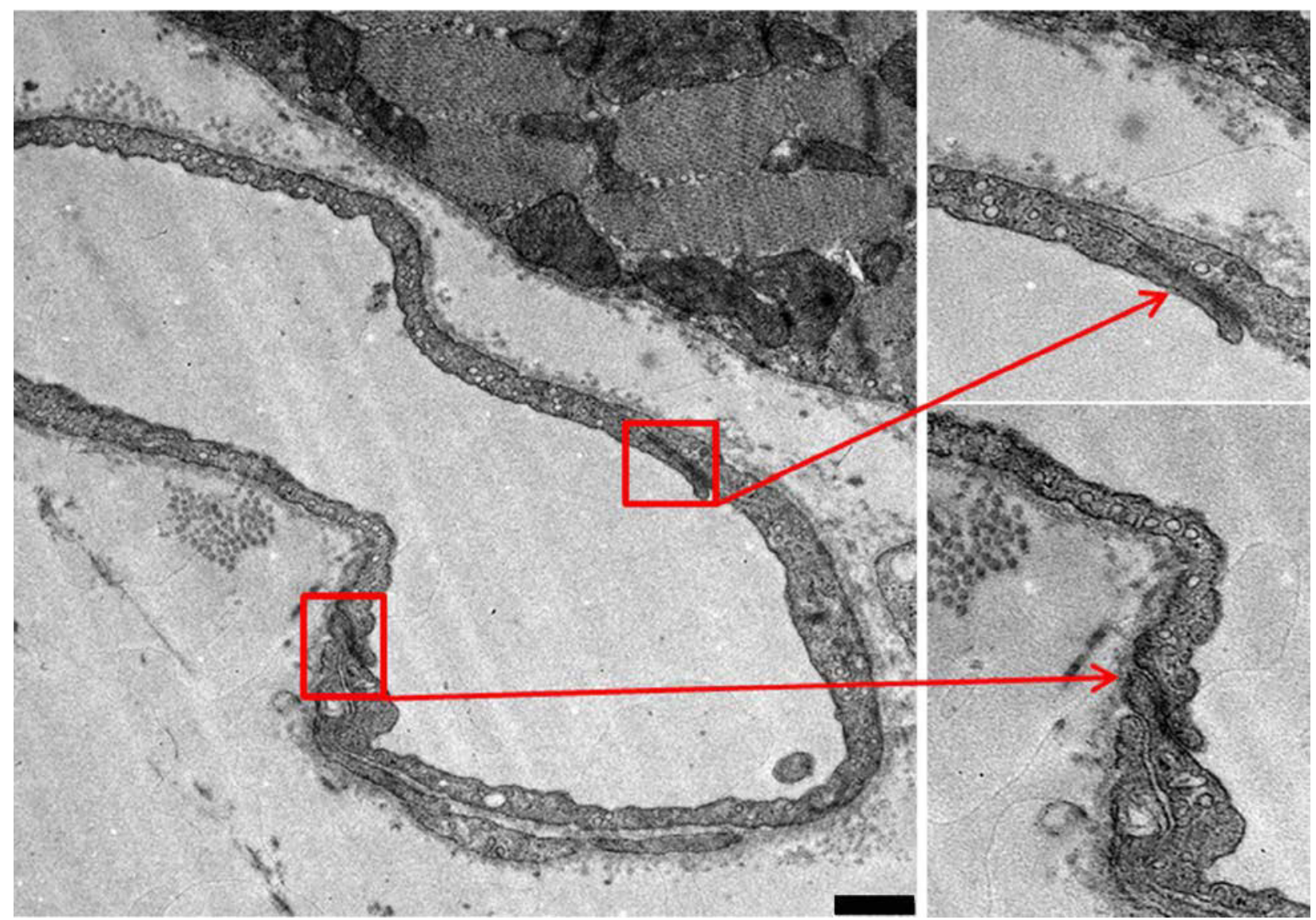

Fig. 1. Representative TEM micrograph of mouse Achilles tendon blood vessel. The endothelium displays a continuous, non-fenestrated endothelium with TJ structures (red arrows). Scale bar: $500 \mathrm{~nm}$.

variation (ANOVA) using the nonparametric KruskalWallis test were used to test for differences between the groups. qPCR data were analysed using the Mann-Whitney test. $p<0.05$ was considered statistically significant.

\section{Results}

In order to characterise a putative BTB in human and mouse tendons which regulates the passage of serum components from the circulation into the tendon tissue, we first set out to demonstrate the presence of structural components known to constitute other tissue barriers. By means of transmission electron microscopy we investigated the ultrastructure of tendon vessels and found that vessels of both the proximal as well as the distal tendon region displayed a continuous, non-fenestrated endothelium with a distinct basal lamina. At higher magnification we identified "kissing points" indicative for tight-junctional complexes (Fig.1).

To demonstrate the presence of tight junctions at the tendon endothelium we performed a qualitative RT-PCR to determine the presence of mRNAs encoding occludin, claudins 1, 3, 4, 5, 7, 11, 12 and 19, as well as Tricellulin using RNA extracted from laser-microdissected human biceps and mouse Achilles tendon blood vessels (Fig.2).

With immunohistochemical staining we tested for several tight junction (TJ)-proteins known to be present at cerebral and retinal endothelial cell junctions.
Immunoreactivity to at least zonula occludens-1 (ZO$1)$, occludin, claudin 3 and claudin 5 was detected in endothelial cells lining the blood vessels of human palmaris longus (Fig. 3a-d), human biceps tendon (data not shown) and mouse Achilles tendons (Fig. 3e-h).

Double immunolabelling using Bandeiraea simplicifolia lectin and antibodies directed against TJ proteins $\mathrm{ZO}$ 1 , occludin, claudin 3 and claudin 5 on mouse Achilles cryosections showed that the TJ-proteins, occludin, claudin 3 and claudin 5 were exclusively localised to the innermost vessel layer, that is the endothelium (Fig. 3e-p).

\section{Tracer studies}

Since the mere presence of tight junction proteins does not necessarily reflect functional tightness of a tissue barrier, we conducted tracer studies by using both a biotinylated $10 \mathrm{kD}$ dextran and a small $287 \mathrm{D}$ neurobiotin tracer. Inspection of the streptavidin-HRP-labelled tissues revealed that the $10 \mathrm{kD}$ tracer remained within the vessel walls of tendon and brain tissue, whereas substantial leakage into the heart muscle was evident (Fig. 4a-f). In contrast, the small tracer was only retained by brain vessels, but passed the endothelium in both the tendon and heart (Fig. 4g-l).

\section{Tendon cell culture \\ Proliferation assay}

To better characterise tendon cell cultures obtained by collagenase II digestion, we stained for markers 

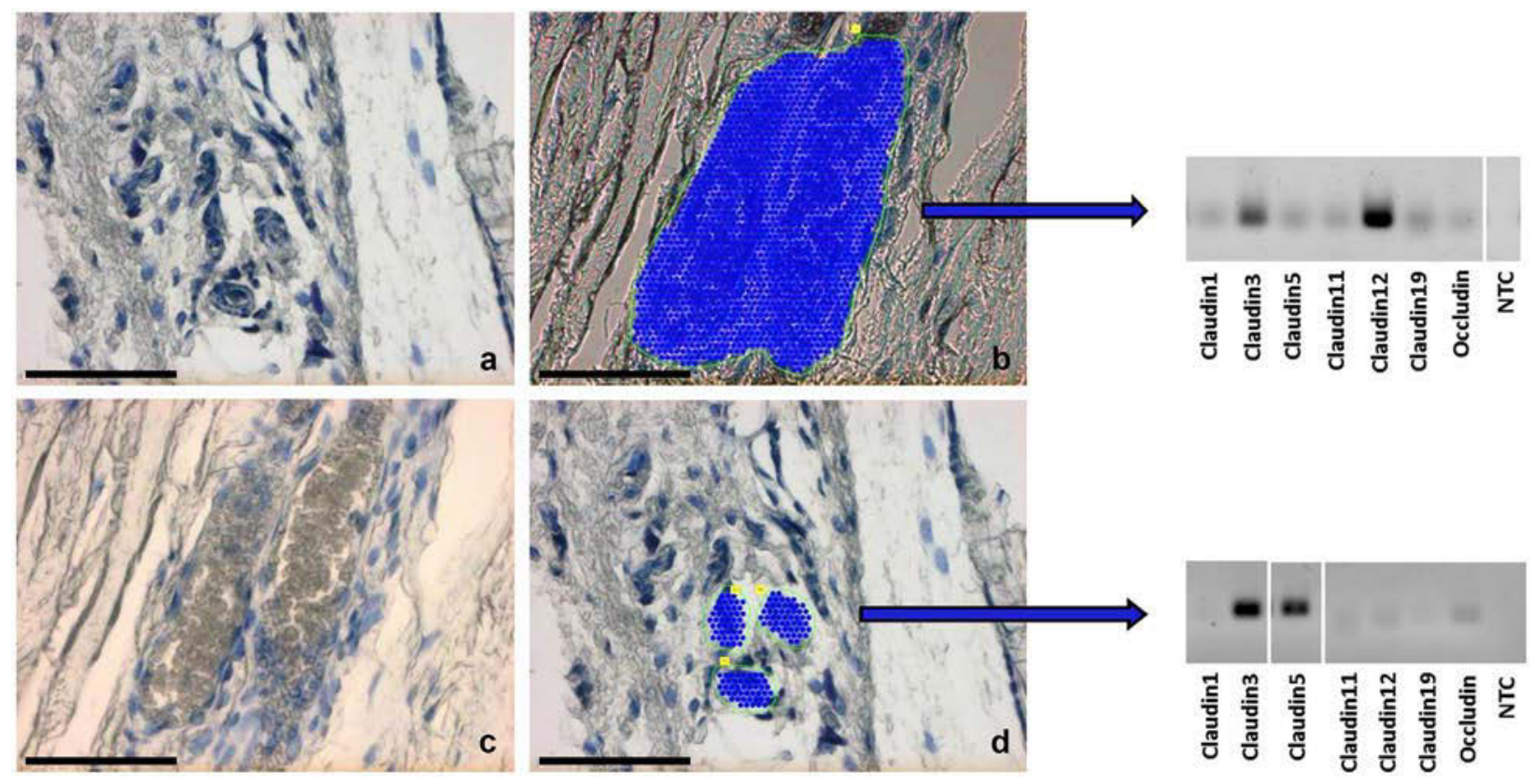

Fig. 2. RT-PCR analysis of RNA isolated from human biceps (a, b) and mouse Achilles tendon (c, d) vessels lasermicrodissected from $6 \mu \mathrm{m}$ thick paraffin sections. mRNAs encoding TJ-associated proteins were analysed. Scale bars: $75 \mu \mathrm{m}$.
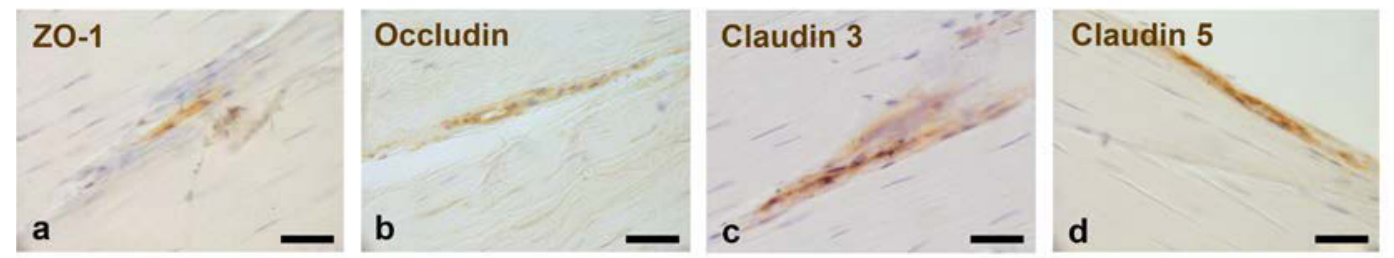

\section{human}
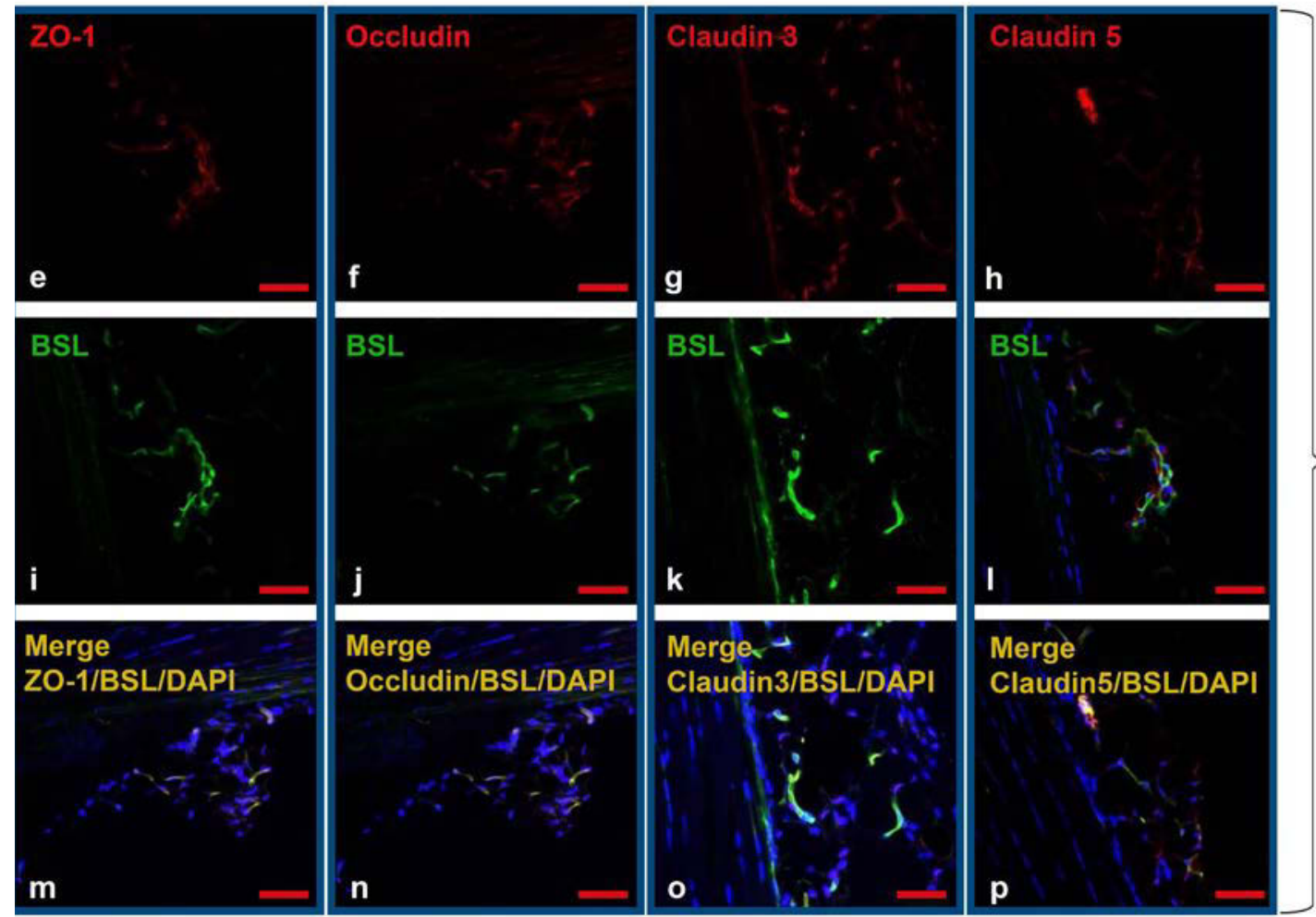

Fig. 3. Immunohistochemical staining of human palmaris longus (a-d) and mouse Achilles tendons (e-p) stained with antibodies directed against ZO-1 (a, e), occludin $(\mathbf{b}, \mathbf{f})$, claudin $3(\mathbf{c}, \mathbf{g})$ and claudin $5(\mathbf{d}, \mathbf{h})$. Blood vessels in mouse Achilles tendons are visualised by Bandeiraea simplicifolia lectin (BSL) (i-l), merged images show co-distribution of ZO-1, occludin, claudin 3 and claudin 5 with BSL, and nuclei are stained with DAPI (m-p). Scale bars: $50 \mu \mathrm{m}$. 


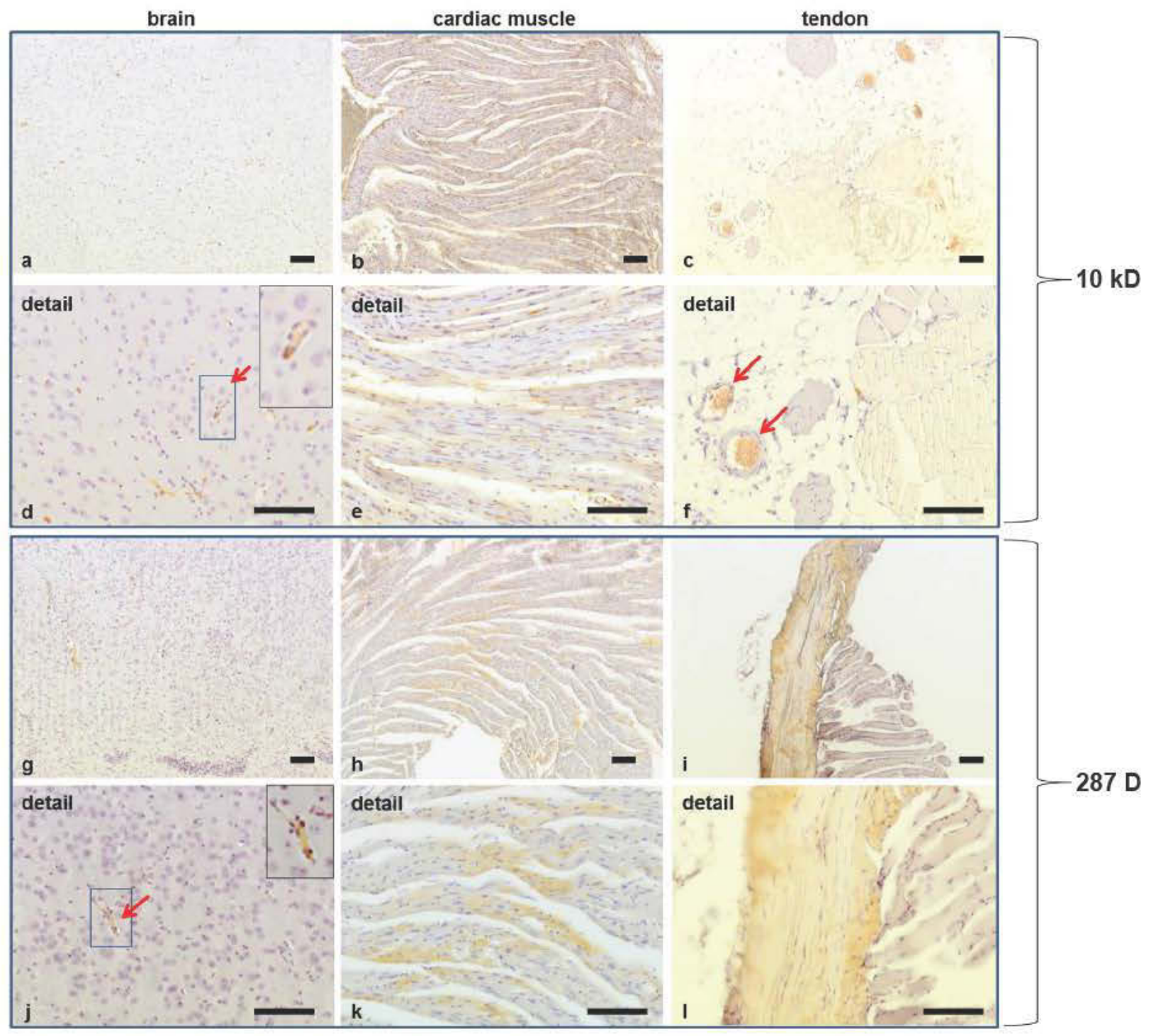

Fig. 4. Biotin immunostaining on paraffin sections of mouse brains $(\mathbf{a}, \mathbf{d}, \mathbf{g}, \mathbf{j})$, cardiac muscles $(\mathbf{b}, \mathbf{e}, \mathbf{h}, \mathbf{k})$ and Achilles tendons $(\mathbf{c}, \mathbf{f}, \mathbf{i}, \mathbf{l})$ of mice perfused with a $10 \mathrm{kD}$ dextran tracer $(\mathbf{a}-\mathbf{f})$ or a $287 \mathrm{D}$ tracer $(\mathbf{g}-\mathbf{l})$ reveal that tendon vessels are tight for the $10 \mathrm{kD}$ tracer trapping it in the lumen (c,f, red arrows), whereas the $287 \mathrm{D}$ tracer leaks out (i,l), causing a homogenous staining. Brain vessels are tight for both tracers (d,j, red arrows). In the cardiac muscle, both tracers leak out from the vessels (b,e,h,k). Scale bars: $100 \mu \mathrm{m}$.

known to be expressed by tendon cells, such as the transmembrane glycoprotein tenomodulin and the intracellular, uncleaved proform of collagen type 1 , the major ECM composing protein within tendons. The tendon cells we cultured homogenously expressed tenomodulin and pro-collagen1a1, CD44, CD29, CD90 and CD105, but lacked CD45 (Fig. 5a-i). We cultured tendon cells in the presence of increasing serum concentrations (Fig. 6a-f). Tendon cell proliferation increased in a serum-dependent manner. After five days of cultivation, the number of cells incubated with $10 \%$ human serum was almost doubled compared to cells treated with $1 \%$ serum. Cells cultured without human serum showed only slight proliferation (Fig. 6a), whereas addition of serum to cultures deprived of serum until day 8 led to immediate cell proliferation, and withdrawal of serum on the day 8 let proliferation go down continuously (Fig. 6g).

\section{Differentiation assays}

To determine whether serum also influences tendon cells apart from proliferation, we applied culture media inducing differentiation into the adipogenic, chondrogenic or osteogenic lineage, respectively. Tendon cells co-incubated with Adipolife $\mathrm{e}^{\mathrm{TM}}$ and serum (with a medium change every other day) for 2 weeks displayed a high amount of lipid droplets visualised by Oil red O staining (Fig. 7b). Differentiation into adipocytes was confirmed by qPCR showing a significant increase in the expression levels of the adipocyte-specific gene PPAR $\gamma(p=0.007)$, compared to tendon cells cultured with Adipolife ${ }^{\mathrm{TM}}$ alone (Fig. 7e).

Tendon cells incubated with Chondrolife ${ }^{\mathrm{TM}}$ exhibited collagen II expression indicative of chondrogenic differentiation (Fig. 8a,b,g). Interestingly, aggrecan expression was predominately present in cell cultures incubated with Chondrolife ${ }^{\mathrm{TM}}$ alone (Fig. 8a,h). In cultures 


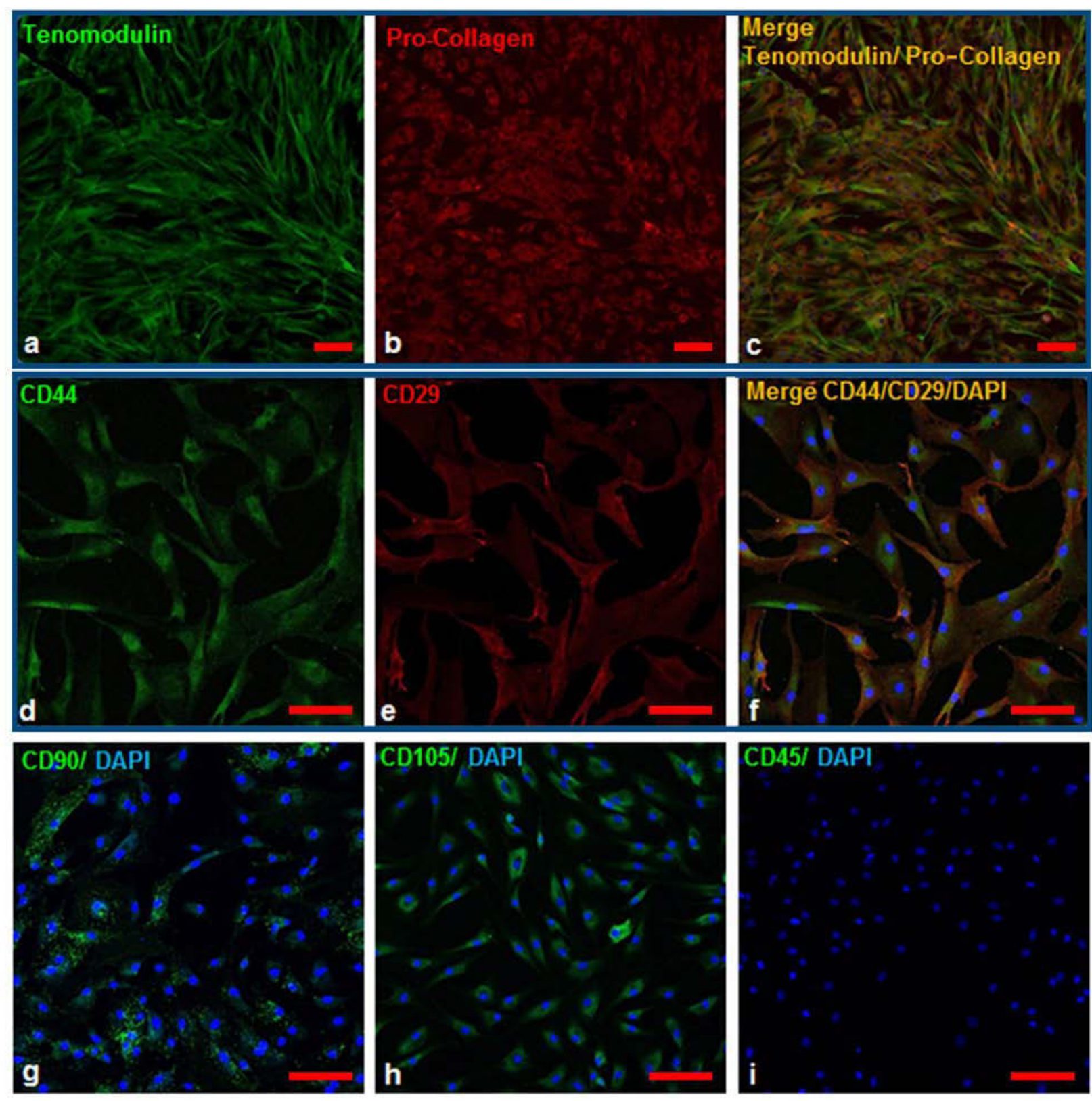

Fig. 5. Immunostaining on human biceps tendon cells show the cells coexpressing tenomodulin and pro-collagen $1 \mathrm{a} 1$ (a-c), CD29 and CD44 (d-f). CD90 (g) and CD105 (h) are expressed, whereas CD45 (i) is not detectable. Scale bars: $100 \mu \mathrm{m}$.

incubated with serum and MEM, staining for neither collagen II nor aggrecan could be detected (Fig. 8c,g,h). Only cells exposed to a standard chondrogenic medium stained for Alcian blue (Fig. 8d,e), a dye staining for acidic sulphated mucosubstances and acetic mucins, whereas cells in control medium displayed a greenish colour (Fig. 8f).

Osteogenic differentiation was assessed by Alizarin $\mathrm{S}$ and alkaline phosphatase staining. The serum-free osteogenic medium Osteolife ${ }^{\mathrm{TM}}$ failed to induce mineral deposition and alkaline phosphatase activity in tendon cells (Fig. 9a,e,h), unless supplemented with $10 \%$ human serum (Fig. 9b,f,i). In serum-free Osteolife ${ }^{\mathrm{TM}}$ treated cultures, only few nodules with calcium deposits were detectable by Alizarin S staining (Fig. 9a). Prominent alkaline phosphatase activity could be detected in tendon cell cultures supplemented with serum irrespective of the addition of Osteolife ${ }^{\mathrm{TM}}$ (Fig. 9f,g,i,j). Semiquantitative analysis of bound Alizarin $\mathrm{S}$ shows that addition of serum causes a significant $(p<0.01) 5.2$ fold increase of mineralisation compared to cultures in unsupplemented Osteolife $^{\text {TM }}$ (Fig. 9d). Since alkaline phosphatase is not exclusively produced by osteoblasts, we performed qPCR for the osteogenesis markers Runx2, BSP1 and PTH1R (Fig. 9k,l,m). Although an increase in expression was evident for all genes, the difference to the control group was statistically not significant.

\section{ß-Galactosidase staining}

The number of senescent cells visualised by $ß$-galactosidase staining showed no difference between treatment groups (data not shown). Under all culture conditions, the number of positive cells was $<0.1 \%$.

Apart from its influence on proliferation and differentiation, serum also affected the expression of the 

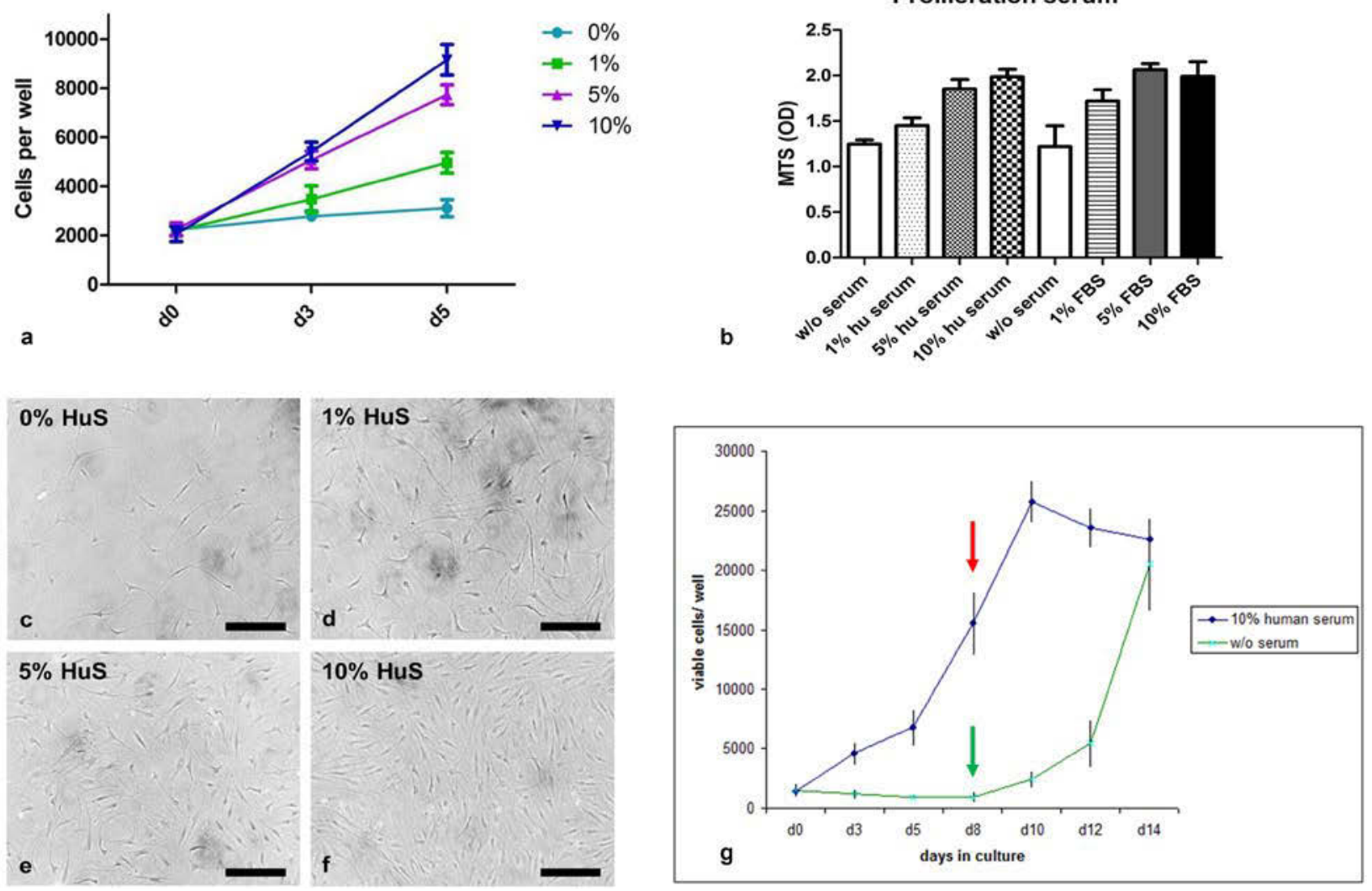

Fig. 6. Proliferation of human tendon cells ( $n=3$ donors) is serum-dependent, as shown by cell counting (a) and MTS assay after $5 \mathrm{~d}$ of culture (b). MTS assay shows no difference in cell proliferation between human and bovine serum (FBS). Representative photomicrographs of human tendon cells cultured for $5 \mathrm{~d}$ at different serum concentrations illustrate the effect of serum on tendon cell proliferation (c-f), Scale bar: $100 \mu \mathrm{m}$. Under serum-free conditions, human tendon cells do not proliferate, addition of serum after $8 \mathrm{~d}$ (green arrow) induces proliferation (g, green line). Serum withdrawal (red arrow) in cells cultured for $8 \mathrm{~d}$ with $10 \%$ human serum leads to an abatement of proliferation (g, blue line).

matrix degrading matrix metalloproteinases MMP2 and MMP9 and of pro-collagen1a1, the precursor form of the ECM building protein collagen1. Whereas MMP2 $(p=0.0572)$ and MMP9 $(p=0.0972)$ expression increased markedly with increasing serum concentration, procollagen 1a1 expression appeared unchanged between 1 and $10 \%$ serum (Fig. 10).

\section{Discussion}

In this work, we focus on the structure, composition and permeability of blood vessels in healthy tendons. Moreover, we show effects of serum on tendon cells in vitro. Our findings provide evidence to suggest the existence of a blood-tissue barrier in tendons allowing the establishment of a stable, internal milieu important for tendon cell proliferation and tendon function.

Since tendons are sparsely vascularised tissues, ultrastructural analysis has so far mainly focussed on fibril size and composition. In our study, therefore, we investigated the ultrastructure of tendon blood vessels. On TEM micrographs we found that tendon vessels display a continuous, non-fenestrated endothelium with junctional complexes between endothelial cells, similar to vessels in the brain and retina (Garbuzova-Davis et al., 2013; Masaki et al., 1995; Wallow and Geldner, 1980).

We further demonstrated the presence of a series of tight junction molecules, both on the RNA as well as the protein level, in human and mouse tendon vessels constituting the prerequisite for the formation of a functional barrier. Interestingly, various core TJ-proteins expressed by tendon endothelial cells (tECs) resemble the set of TJ-proteins expressed at the blood-brain barrier (BBB) and the bloodretina barrier (BRB). At the TJs of central nervous system (CNS)-capillaries, occludin, ZO-1, claudin 3 and claudin 5 have been detected in both human and mouse (Nitta et al., 2003; Schrade et al., 2012; Wolburg et al., 2003). In rodent retinal endothelial cells, the TJ-proteins ZO-1, occludin, claudin $1 / 3$, claudin 2 , claudin 5 and JAM1 have been shown to be expressed (Klaassen et al., 2009; Luo et al., 2011; Xu et al., 2005), and claudin 12 transcripts have been detected in bovine retinal endothelial cells (Klaassen et al., 2009). Claudins 1,3 and 5 are considered to be barrier-sealing proteins (Pfeiffer et al., 2011; Zhang et al., 2010a). In overexpression experiments using MadinDarby canine kidney (MDCK) cells, Milatz et al. (2010) showed that claudin 3 acts as a barrier-forming tight 

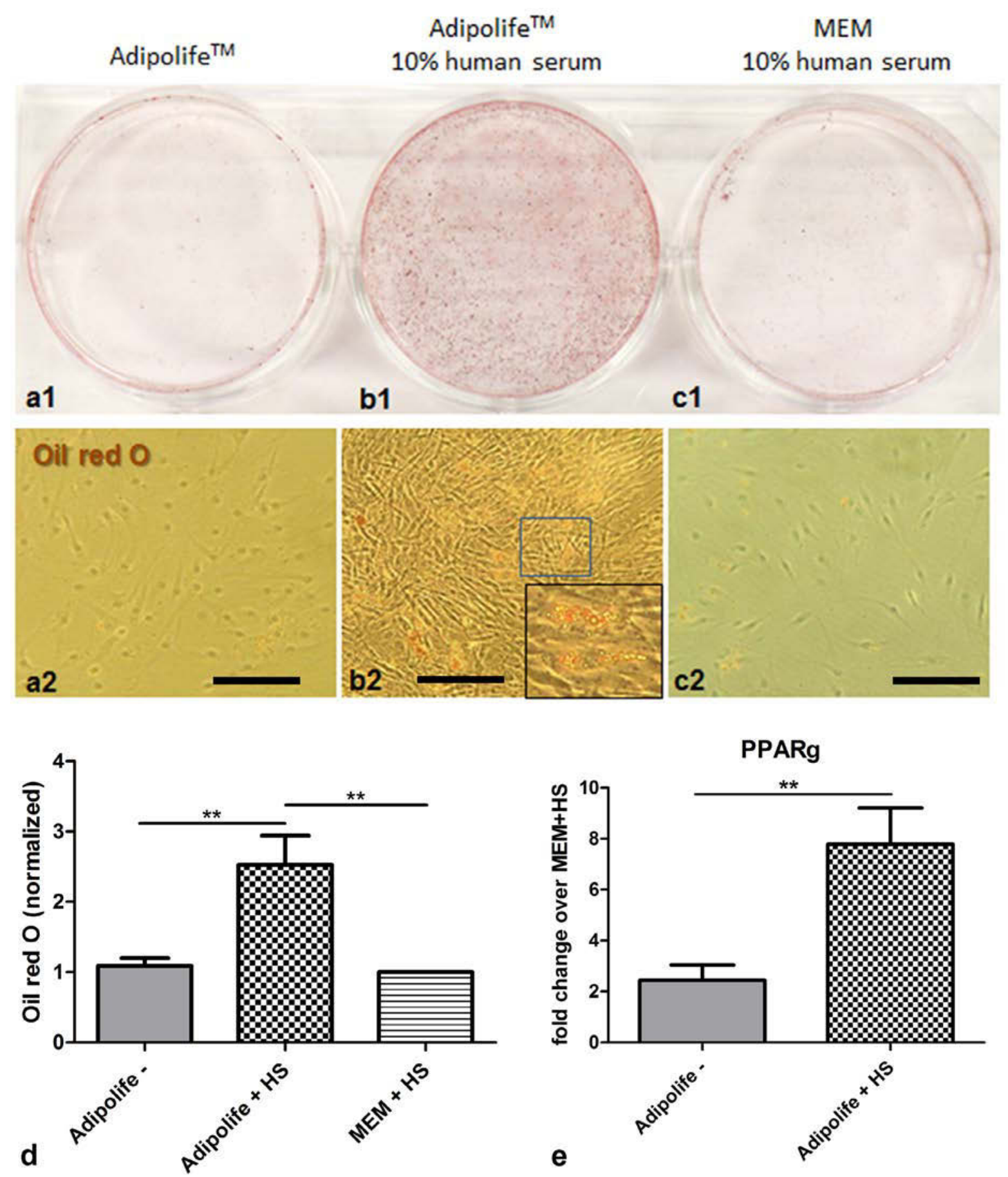

Fig. 7. Oil red O staining of human tendon cells cultured with Adipolife ${ }^{\mathrm{TM}}$ (a1 overview, a2 photomicrograph), Adipolife ${ }^{\mathrm{TM}}$ supplemented with $10 \%$ human serum (b1 overview, b2 photomicrograph), and MEM with $10 \%$ human serum (c1 overview, c2 photomicrograph) reveals that serum promotes the formation of lipid droplets. Scale bar: $100 \mu \mathrm{m}$. Semiquantitative analysis of bound Oil red O shows that addition of serum causes a significant $(* * p<0.01)$ 2.5 fold upregulation of lipid droplets (d). Transcripts of PPAR $\gamma$ are significantly $(* * p<0.01)$ upregulated in the cells cultured with Adipolife ${ }^{\mathrm{TM}}$ and human serum (e). Scale bars: $150 \mu \mathrm{m}$.

junction component that strongly reduces the paracellular permeability to ions and larger uncharged solutes but not to osmotically driven water.

It is well established that composition and architecture of junctional complexes are critically involved in regulating vessel permeability (Bazzoni, 2006). Tendon vasculature in general and tendon vessel properties in particular have hardly been investigated so far. To our knowledge, no data on the permeability of tendon vessels exist. Our tracer studies revealed that mouse tendon vessels, in contrast to heart vessels, are tight to a $10 \mathrm{kD}$ tracer, but not to a $287 \mathrm{D}$ tracer, suggesting that tendon vessels are not as tight as brain capillaries which exclude both tracers. The fact that the $10 \mathrm{kD}$ tracer does not permeate the blood vessel wall implies that most serum proteins are excluded from paracellular entry into the tendon tissue. However, we 


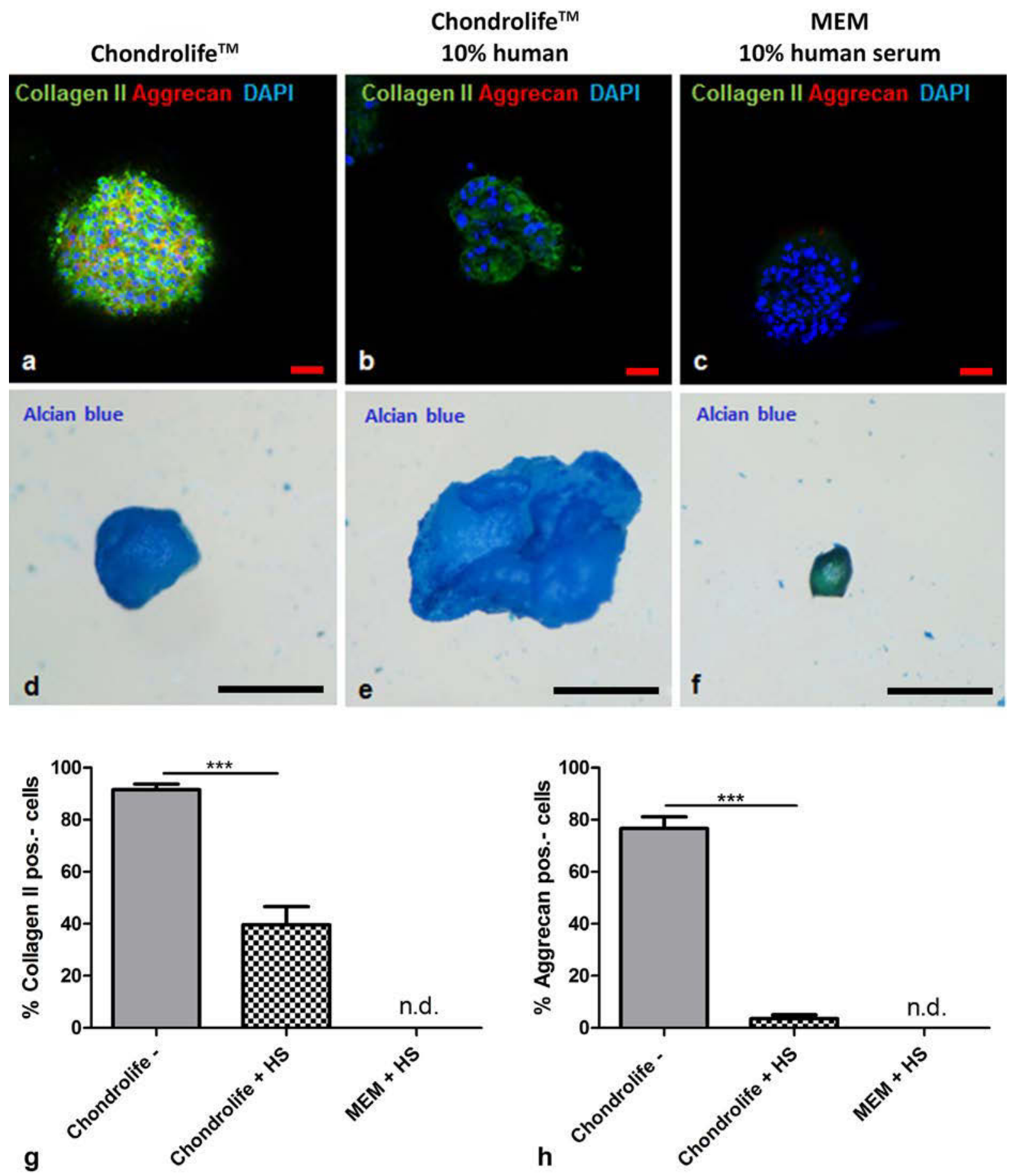

Fig. 8. Immunohistochemical staining of pellet cultures from human tendon cells (a-c) show that collagen type II (91.6\% cells positive, $\mathbf{g})$ and aggrecan $(76.7 \%$ positive, $\mathbf{h})$ are expressed when the pellets were cultured in unsupplemented Chondrolife ${ }^{\mathrm{TM}}$. Upon culture in Chondrolife ${ }^{\mathrm{TM}}$ supplemented with $10 \%$ human serum, collagen type II is expressed by $39.6 \%$ of all cells (g) and aggrecan by $3.6 \%$ (h). Neither collagen type II nor aggrecan are detectable when cells were cultured in MEM and serum $(\mathbf{g}, \mathbf{h})(* * * p<0.001)$. The pellets are positive for Alcian blue staining under all conditions (d-f). Scale bars: $50 \mu \mathrm{m}(\mathbf{a}-\mathbf{c}), 1 \mathrm{~mm}(\mathbf{d}-\mathbf{f})$.

cannot exclude an active transport via a transporter protein mediating transcellular passage.

Modulation of vessel permeability by altered TJ composition has clearly been shown by Nitta et al. (2003). By performing tracer experiments in claudin 5-deficient mice, the authors demonstrated a size-selective increase in the permeability of morphologically normal blood vessels allowing the passage of small $(<800 \mathrm{D})$, but not larger molecules.
Since the charge- and size-selective properties of the paracellular barrier are determined by the combination and interaction of the claudin family members present within a cell, alterations in the expression of these proteins have a strong influence on ion homeostasis and, thus, the microenvironment of the tissue niche (Mizutani et al., 1995; Wolburg et al., 2003).

In order to obtain information on the effects of serum on tendon cells, we utilised an in vitro approach to mimic blood 


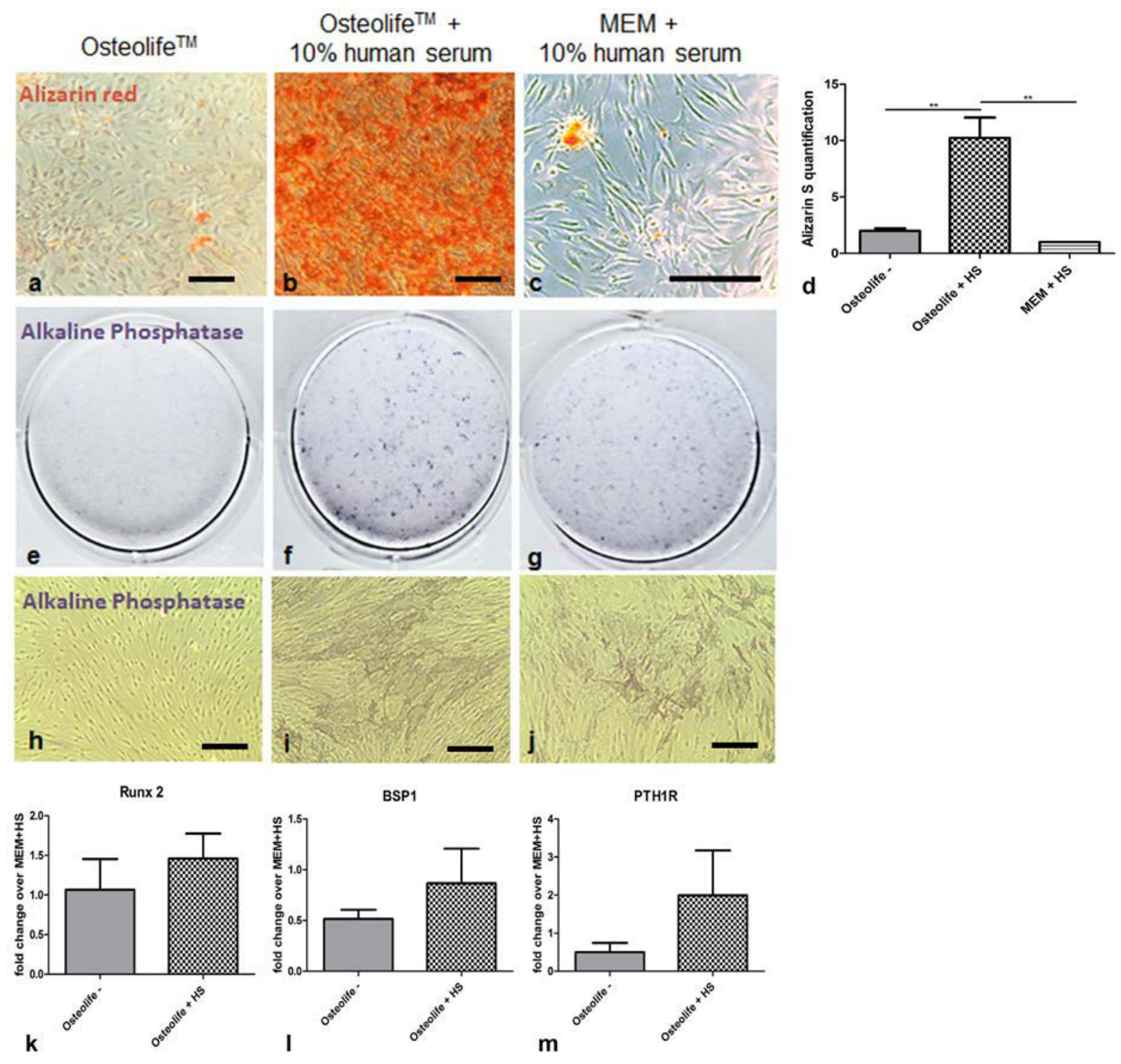

Fig. 9. Alizarin S staining of human tendon cells cultured with Osteolife ${ }^{\mathrm{TM}}(\mathbf{a})$, Osteolife ${ }^{\mathrm{TM}}$ supplemented with $10 \%$ human serum (b), and MEM with $10 \%$ human serum (c) reveals that serum promotes the deposition of minerals. Scale bars: $100 \mu \mathrm{m}$. Semiquantitative analysis of bound Alizarin S shows that addition of serum causes a significant $(* * p<0.01) 10.3$ fold increase of mineralisation $(\mathbf{d})$. Alkaline phosphatase (AP) staining shows no AP activity in cells cultured with Osteolife ${ }^{\mathrm{TM}}$, whereas AP activity is detectable in cells cultured in Osteolife ${ }^{\mathrm{TM}}$ with serum and in cells cultured with MEM and serum (e-g overviews, h-j photomicrographs - Scale bars: $150 \mu \mathrm{m})$. Quantitative RTPCR shows that Runx2 (k), BSP1 (l) and PTH1R (m) transcripts showed a trend of upregulation in cells cultured in Osteolife ${ }^{\mathrm{TM}}$ supplemented with $10 \%$ human serum.

vessel leakage by adding increasing amounts of human serum to the culture medium. We found that serum seems to play a fundamental role in proliferation and differentiation of human tendon cells and their expression of matrixforming and matrix-degrading proteins. Under adipogenic culture conditions, serum promoted the formation of cytoplasmic lipid droplets and significantly increased the expression of the ligand-activated transcription factor PPAR $\gamma$, which is the master regulator of adipogenesis (Rosen and Spiegelman, 2001). In contrast, Adipolife ${ }^{\mathrm{TM}}$ culture medium without serum did not induce adipogenesis. From these results, we conclude that tendon cells need both a stimulus directing the cells towards an adipogenic differentiation programme and the presence of serum for final maturation into fat cells. While Osteolife ${ }^{\mathrm{TM}}$ without serum triggered only a small population of tendon cells to deposit calcium crystals, addition of serum substantially increased the percentage of cells containing calcium deposits. This finding indicates that serum increases the susceptibility of tendon-derived cells to osteogenic stimuli. In contrast, successful osteogenic differentiation of MSCs cultured in Osteolife ${ }^{\mathrm{TM}}$ does not require the presence of serum (Bortolotti et al., 2015; Uzer et al., 2013).

Interestingly, differentiation of tendon-derived cells into the chondrogenic lineage did not seem to be serumdependent. Aggrecan, the cartilage-specific proteoglycan core protein, appeared to be expressed in cells cultured in Chondrolife ${ }^{\mathrm{TM}}$ medium without serum supplementation. Expression of collagen II, the predominant collagen type in articular cartilage, was induced by Chondrolife ${ }^{\mathrm{TM}}$ in both 

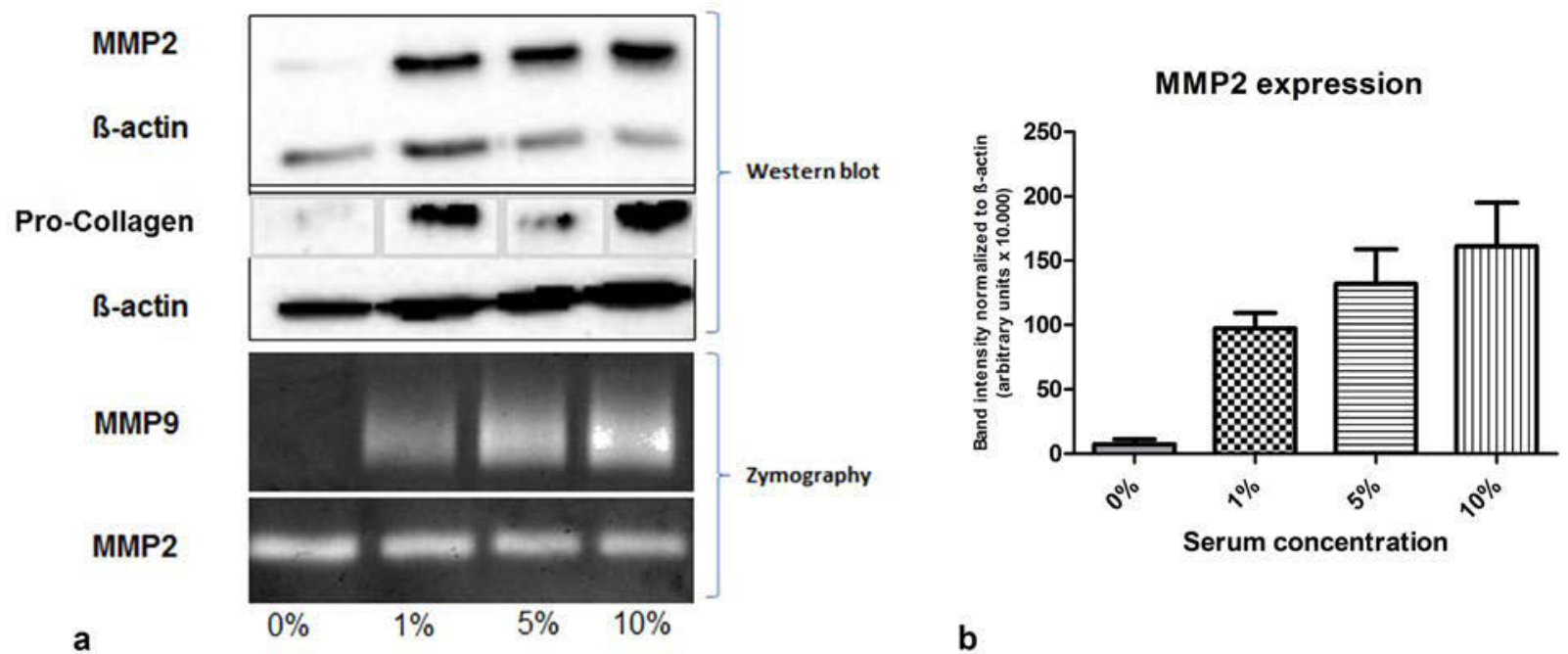

b
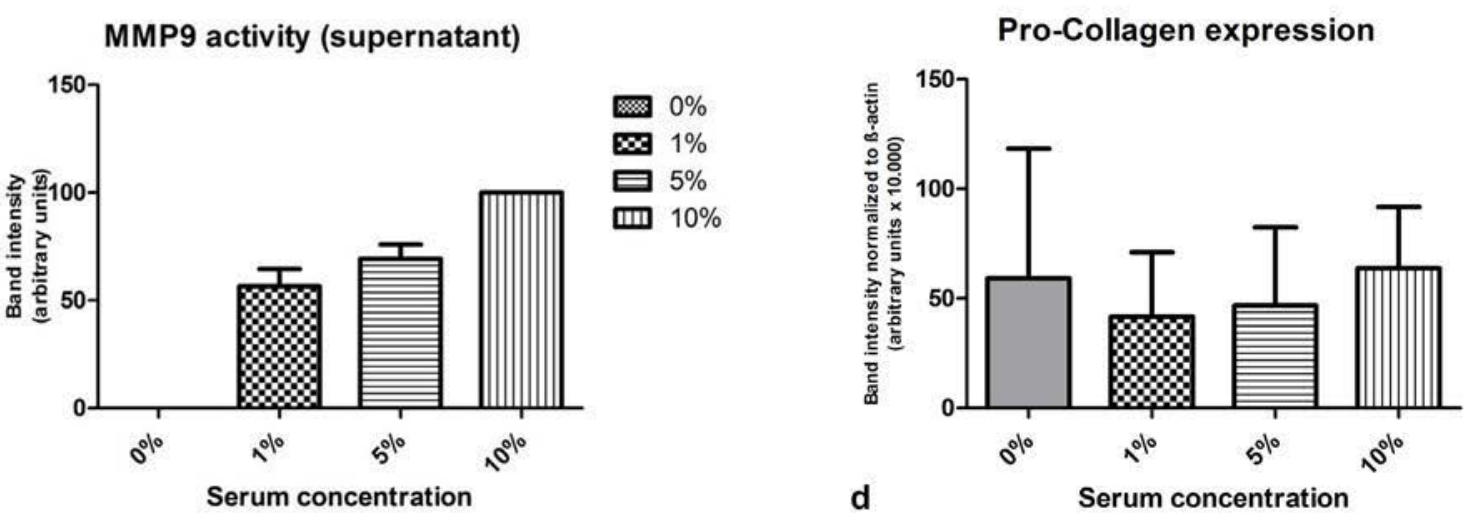

Fig. 10. Representative Western blots and zymograms of human tendon cell lysates showing MMP2, MMP9, and Pro-collagen la1 expression of human tendon cells in dependence of different serum concentrations $(0,1,5$ and $10 \%)$. ß-actin serves as loading control (a). Corresponding densitometric quantification of expression levels of MMP2 (b), MMP9 (c) and Pro-collagen1a1 (d) from three different experiments are normalised to $\beta$-actin.

the absence and presence of serum. The same applied for proteoglycans evidenced by Alcian blue staining.

Future studies will have to address the potential role of the described vascular barrier in the diseased tendon. This is tempting, as there are many parallels between our in vitro observations and symptoms known from diseased tendons:

1. Tissue turnover and cell proliferation are very limited in healthy tendons (Heinemeier et al., 2013), in diseased tendons hypercellularity and hyperproliferation are common features (Rolf et al., 2001). In our work, we show that serum strongly affects tendon cell proliferation. Tendon cells hardly proliferate when cultured without serum. Upon addition of serum, cells immediately started to divide (Fig. 6g).

2. In tendinopathic or tenotomised tendons, calcification and ossification processes, mucoid and fatty infiltrations have been observed (Buck et al., 2009; Mavrikakis et al., 1989; McClure, 1983; Oliva et al., 2012), the underlying mechanism for it being largely unknown. In this work, we show that serum contact is crucial for tendon-resident cells to undergo differentiation to the osteoblast and adipocyte lineage.

3. Remodelling processes, occurring in tendinopathic and ruptured tendons, correspond to an increased expression of MMP2 and MMP9 (Alfredson et al., 2003; Robertson et al., 2012). Our results demonstrated that serum increases the expression of the ECM degrading matrix metalloproteinases MMP2 and MMP9. Pro-collagen1a1, the major matrix constituting protein, does not show comparable serum dependence. Pro-collagen1a1 levels appear similar in tendon cell cultures supplemented with 1 or $10 \%$ human serum. Apparently, tendon cells do not require high serum concentrations since they are capable of producing collagens also under low serum conditions (Fig. 10d).

To underpin a putative role of an impaired barrier in tendon disorders, the permeability status and TJ expression of blood vessels in compromised (e.g. diabetic) tendons will be in the focus of our future studies.

If tendon degenerative processes are a consequence of, or at least abated by, increased permeability of leaky tendon vessels, the application of drugs leading to a barrier tightening might be a feasible strategy to slow down or halt this detrimental progression. Therefore, restoration of a functional barrier and consequently the niche may stand at the basis for promising regeneration. 


\section{Conclusion}

We provide evidence for a TJ-based blood-tendon barrier restricting the passage of molecules larger than $10 \mathrm{kD}$. This barrier contributes to the niche in which tendon stem cells reside and differentiate and may be a novel therapeutic target in tendon regeneration strategies.

\section{Acknowledgements}

We would like to thank Prof. Dr. Wolf-Dietrich Krautgartner and Ing. Michaela Klappacher from the Department of Organismic Biology of the University of Salzburg for technical support and for providing access to the electron microscope facility. Moreover, we acknowledge Dr. Katja Heinemeier and Dr. Peter Schjerling from the Institute of Sports Medicine of the University of Copenhagen for their collaboration and scientific input. The authors would like to acknowledge funding from the Paracelsus Medical University (project R-10/05/022-LEH), the Herrmann and Marianne Straniak Foundation (Sarnen, Switzerland) and the Lorenz Böhler Funds (Vienna, Austria). We wish to confirm that there are no known conflicts of interest associated with this publication and there has been no significant financial support for this work that could have influenced its outcome.

\section{References}

Abbott NJ, Patabendige AA, Dolman DE, Yusof SR, Begley DJ (2010) Structure and function of the blood-brain barrier. Neurobiol Dis 37: 13-25.

Ahmed IM, Lagopoulos M, McConnell P, Soames RW, Sefton GK (1998) Blood supply of the Achilles tendon. J Orthop Res 16: 591-596.

Alfredson H, Lorentzon M, Backman S, Backman A, Lerner UH (2003) cDNA-arrays and real-time quantitative PCR techniques in the investigation of chronic Achilles tendinosis. J Orthop Res 21: 970-975.

Andersson G, Backman LJ, Scott A, Lorentzon R, Forsgren S, Danielson P (2011) Substance P accelerates hypercellularity and angiogenesis in tendon tissue and enhances paratendinitis in response to Achilles tendon overuse in a tendinopathy model. Br J Sports Med 45: 1017-1022.

Astrom M, Rausing A (1995) Chronic Achilles tendinopathy. A survey of surgical and histopathologic findings. Clin Orthop Relat Res 316:151-164.

Bauer HC, Traweger A, Zweimueller-Mayer J, Lehner C, Tempfer H, Krizbai I, Wilhelm I, Bauer H (2011) New aspects of the molecular constituents of tissue barriers. J Neural Transm 118: 7-21.

Bauer HC, Krizbai IA, Bauer H, Traweger A (2014) "You Shall Not Pass"-tight junctions of the blood brain barrier. Front Neurosci 8: 392.

Bazzoni G (2006) Endothelial tight junctions: permeable barriers of the vessel wall. Thromb Haemost 95: $36-42$.
Bi Y, Ehirchiou D, Kilts TM, Inkson CA, Embree MC, Sonoyama W, Li L, Leet AI, Seo BM, Zhang L, Shi S, Young MF (2007) Identification of tendon stem/progenitor cells and the role of the extracellular matrix in their niche. Nat Med 13: 1219-1227.

Bortolotti F, Ukovich L, Razban V, Martinelli V, Ruozi G, Pelos B, Dore F, Giacca M, Zacchigna S (2015) In vivo therapeutic potential of mesenchymal stromal cells depends on the source and the isolation procedure. Stem Cell Reports 4: 332-339.

Buck FM, Grehn H, Hilbe M, Pfirrmann CW, Manzanell S, Hodler J (2009) Degeneration of the long biceps tendon: comparison of MRI with gross anatomy and histology. Am J Roentgenol 193: 1367-1375.

Dimri GP, Lee X, Basile G, Acosta M, Scott G, Roskelley C, Medrano EE, Linskens M, Rubelj I, PereiraSmith O (1995) A biomarker that identifies senescent human cells in culture and in aging skin in vivo. Proc Natl Acad Sci USA 92: 9363-9367.

Fenwick SA, Hazleman BL, Riley GP (2002) The vasculature and its role in the damaged and healing tendon. Arthritis Res 4: 252-260.

Garbuzova-Davis S, Mirtyl S, Sallot SA, HernandezOntiveros DG, Haller E, Sanberg PR (2013) Blood-brain barrier impairment in MPS III patients. BMC Neurol 13: 174.

Hagberg L, Heinegard D, Ohlsson K (1992) The contents of macromolecule solutes in flexor tendon sheath fluid and their relation to synovial fluid. A quantitative analysis. J Hand Surg Br 17: 167-171.

Heinemeier KM, Schjerling P, Heinemeier J, Magnusson SP, Kjaer M (2013) Lack of tissue renewal in human adult Achilles tendon is revealed by nuclear bomb (14)C. FASEB J 27: 2074-2079.

Hooper G, Davies R, Tothill P (1984) Blood flow and clearance in tendons. Studies with dogs. J Bone Joint Surg Br 66: 441-443.

Jones M, Clayton E, Noel C, Ladhani K, Grobbelaar A (2003) Immunohistochemical endothelial localisation - a novel method of vessel delineation in tendon tissue. $\mathrm{J}$ Immunol Methods 280: 175-181.

Kannus P (2000) Structure of the tendon connective tissue. Scand J Med Sci Sports 10: 312-320.

Katenkamp D, StillerD, Schulze E(1976) Ultrastructural cytology of regenerating tendon - an experimental study. Exp Pathol 12: 25-37.

Klaassen I, Hughes JM, Vogels IM, Schalkwijk CG, Van Noorden CJ, Schlingemann RO (2009) Altered expression of genes related to blood-retina barrier disruption in streptozotocin-induced diabetes. Exp Eye Res 89: 4-15.

Krizbai IA, Bauer H, Amberger A, Hennig B, Szabó H, Fuchs R, Bauer HC (2000) Growth factor-induced morphological, physiological and molecular characteristics in cerebral endothelial cells. Eur J Cell Biol 79: 594-600.

Legerlotz K, Dorn J, Richter J, Rausch M, Leupin O (2014) Age-dependent regulation of tendon crimp structure, cell length and gap width with strain. Acta Biomater 10: 4447-4455.

Lui PP (2013) Identity of tendon stem cells - how much do we know? J Cell Mol Med 17: 55-64. 
Lundborg G, Holm S, Myrhage R (1980) The role of the synovial fluid and tendon sheath for flexor tendon nutrition. An experimental tracer study on diffusional pathways in dogs. Scand J Plast Reconstr Surg 14: 99-107.

Luo Y, Xiao W, Zhu X, Mao Y, Liu X, Chen X, Huang J, Tang S, Rizzolo LJ (2011) Differential expression of claudins in retinas during normal development and the angiogenesis of oxygen-induced retinopathy. Invest Ophthalmol Vis Sci 52: 7556-7564.

Manske PR, Lesker PA(1985) Flexor tendon nutrition. Hand Clin 1: 13-24.

Masaki H, Atsumi T, Sakurai H (1995) Protective activity of hamamelitannin on cell damage of murine skin fibroblasts induced by UVB irradiation. J Dermatol Sci 10: 25-34.

Mavrikakis ME, Drimis S, Kontoyannis DA, Rasidakis A, Moulopoulou ES, Kontoyannis S (1989) Calcific shoulder periarthritis (tendinitis) in adult onset diabetes mellitus: a controlled study. Ann Rheum Dis 48: 211-214.

Mazzocca AD, McCarthy MB, Chowaniec DM, Dugdale EM, Hansen D, Cote MP, Bradley JP, Romeo AA, Arciero RA, Beitzel K (2012) The positive effects of different platelet-rich plasma methods on human muscle, bone, and tendon cells. Am J Sports Med 40: 1742-1749.

McClure J (1983) The effect of diphosphonates on heterotopic ossification in regenerating Achilles tendon of the mouse. J Pathol 139: 419-430.

Milatz S, Krug SM, Rosenthal R, Günzel D, Müller D, Schulzke JD, Amasheh S, Fromm M (2010) claudin-3 acts as a sealing component of the tight junction for ions of either charge and uncharged solutes. Biochim Biophys Acta 1798: 2048-2057.

Mizutani K, Ito M, Nakano T, Kamiya H, Sakurai M (1995) Impaired expression of interleukin 2 receptor and CD45RO antigen on lymphocytes from children with acute lymphoblastic leukemia in response to cytomegalovirus and varicella-zoster virus. Clin Diagn Lab Immunol 2: 381-384.

Nitta T, Hata M, Gotoh S, Seo Y, Sasaki H, Hashimoto N, Furuse M, Tsukita S (2003) Size-selective loosening of the blood-brain barrier in claudin-5-deficient mice. J Cell Biol 161: 653-660.

Oliva F, Via AG, Maffulli N (2012) Physiopathology of intratendinous calcific deposition. BMC Med 10: 95.

Pfeiffer F, Schafer J, Lyck R, Makrides V, Brunner S, Schaeren-Wiemers N, Deutsch U, Engelhardt B (2011) Claudin-1 induced sealing of blood-brain barrier tight junctions ameliorates chronic experimental autoimmune encephalomyelitis. Acta Neuropathol 122: 601-614.

Robertson CM, Chen CT, Shindle MK, Cordasco FA, Rodeo SA, Warren RF (2012) Failed healing of rotator cuff repair correlates with altered collagenase and gelatinase in supraspinatus and subscapularis tendons. Am J Sports Med 40: 1993-2001.

Rolf CG, Fu BS, Pau A, Wang W, Chan B (2001) Increased cell proliferation and associated expression of PDGFRbeta causing hypercellularity in patellar tendinosis. Rheumatology 40: 256-261.

Rosen ED, Spiegelman BM (2001) PPARgamma : a nuclear regulator of metabolism, differentiation, and cell growth. J Biol Chem 276: 37731-37734.
Rui YF, Lui PP, Chan LS, Chan KM, Fu SC, Li G (2011a) Does erroneous differentiation of tendon-derived stem cells contribute to the pathogenesis of calcifying tendinopathy? Chin Med J 124: 606-610.

Rui YF, Lui PP, Ni M, Chan LS, Lee YW, Chan KM (2011b) Mechanical loading increased BMP-2 expression which promoted osteogenic differentiation of tendonderived stem cells. J Orthop Res 29: 390-396.

Schrade A, Sade H, Couraud PO, Romero IA, Weksler BB, Niewoehner J (2012) Expression and localization of claudins-3 and -12 in transformed human brain endothelium. Fluids Barriers CNS 9: 6.

Tempfer H, Traweger A (2015) Tendon vasculature in health and disease. Front Physiol 6: 330.

Tempfer H, Wagner A, Gehwolf R, Lehner C, Tauber M, Resch H, Bauer HC (2009) Perivascular cells of the supraspinatus tendon express both tendon- and stem cellrelated markers. Histochem Cell Biol 131: 733-741.

Tong WY, Shen W, Yeung CW, Zhao Y, Cheng SH, Chu PK, Chan D, Chan GC, Cheung KM, Yeung KW, Lam YW (2012) Functional replication of the tendon tissue microenvironment by a bioimprinted substrate and the support of tenocytic differentiation of mesenchymal stem cells. Biomaterials 33: 7686-7698.

Traweger A, Lehner C, Farkas A, Krizbai IA, Tempfer H, Klement E, Guenther B, Bauer HC, Bauer H (2008) Nuclear Zonula occludens-2 alters gene expression and junctional stability in epithelial and endothelial cells. Differentiation 76: 99-106.

Uzer G, Pongkitwitoon S, Ete Chan M, Judex S (2013) Vibration induced osteogenic commitment of mesenchymal stem cells is enhanced by cytoskeletal remodeling but not fluid shear. J Biomech 46: 2296-2302.

Vandesompele J, De Preter K, Pattyn F, Poppe B, Van Roy N, De Paepe A, Speleman F (2002) Accurate normalization of real-time quantitative RT-PCR data by geometric averaging of multiple internal control genes. Genome Biol 3: RESEARCH0034.

Wallow IH, Geldner PS (1980) Endothelial fenestrae in proliferative diabetic retinopathy. Invest Ophthalmol Vis Sci 19: 1176-1183.

Wang B, Liu W, Zhang Y, Jiang Y, Zhang WJ, Zhou G, Cui L, Cao Y (2008) Engineering of extensor tendon complex by an ex vivo approach. Biomaterials 29: 29542961.

Wang X, Qiu Y, Triffitt J, Carr A, Xia Z, Sabokbar A (2012) Proliferation and differentiation of human tenocytes in response to platelet rich plasma: an in vitro and in vivo study. J Orthop Res 30: 982-990.

Weidman KA, Simonet WT, Wood MB, Cooney WP 3rd, Ilstrup DM (1984) Quantification of regional blood flow to canine flexor tendons. J Orthop Res 2: 257-261.

Wolburg H, Wolburg-Buchholz K, Kraus J, RascherEggstein G, Liebner S, Hamm S, Duffner F, Grote EH, Risau W, Engelhardt B (2003) Localization of claudin-3 in tight junctions of the blood-brain barrier is selectively lost during experimental autoimmune encephalomyelitis and human glioblastoma multiforme. Acta Neuropathol 105: 586-592.

$\mathrm{Xu}$ H, Dawson R, Crane IJ, Liversidge J (2005) Leukocyte diapedesis in vivo induces transient loss of 
tight junction protein at the blood-retina barrier. Invest Ophthalmol Vis Sci 46: 2487-2494.

Zhang J, Wang JH (2013) Human tendon stem cells better maintain their stemness in hypoxic culture conditions. PLoS One 8: e61424.

Zhang ZZ, Zhong SZ, Sun B, Ho GT (1990) Blood supply of the flexor digital tendon in the hand and its clinical significance. Surg Radiol Anat 12: 113-117.

Zhang J, Piontek J, Wolburg H, Piehl C, Liss M, Otten C, Christ A, Willnow TE, Blasig IE, Abdelilah-Seyfried S (2010a) Establishment of a neuroepithelial barrier by claudin5a is essential for zebrafish brain ventricular lumen expansion. Proc Natl Acad Sci USA 107: 1425-1430.

Zhang Y, Wang B, Zhang WJ, Zhou G, Cao Y, Liu W (2010b) Enhanced proliferation capacity of porcine tenocytes in low $\mathrm{O} 2$ tension culture. Biotechnol Lett 32: 181-187.

\section{Discussion with Reviewers}

Reviewer I: The potential involvement of the tendonblood barrier in the development of tendinopathies is an interesting idea, which does indeed lend itself to be tested in an animal model. Particularly as to date there are no valid tendinopathy animal models out there, what would your approach be to translate/transfer that idea into an animal model?

Authors: We agree with the reviewer regarding the notion that there is no valid tendinopathy small animal model available. If there was, we would tracer inject such animals and look whether the tracer leaks out of the vessels. Naturally occurring tendinopathies in horses are due to size reasons no option for tracer perfusion. One approach to test our hypothesis could be to make the barrier leaky by mannitol injection and look whether a tendinopathy develops.

Reviewer I: How does the concept of a tendon blood barrier fit in with current tendinopathy treatment methods? On the one hand, sclerosing agents are used to destroy neovessels, whereas on the other hand, platelet rich plasma (PRP) is injected into the tendon to promote healing.

Authors: The concept of a blood-tendon barrier fits in well with the reported efficacy of sclerosing agents shown to destroy neovessels. Reduction of leaky neovessels reduces extravasation of serum into the surrounding tissue and consequently, in line with our in vitro observations, proliferation and erroneous differentiation of tendon cells. Interestingly, methods shown to be beneficial for treatment of tendinopathies at high levels of evidence, such as eccentric loading, reduce tendon vascularity. Injection of platelet rich plasma into the tendon is believed to promote cell proliferation and angiogenesis by delivery of various growth factors such as vascular endothelial growth factor and is therefore regarded to promote the healing process. But so far there is no convincing evidence from studies with high levels of evidence that treatment of diseased tendons with PRP is superior to control treatments. The findings presented in this paper may shed new light on potential mechanisms of PRP on tendon tissue.

Editor's Note: Scientific Editor in charge of the paper: Juerg Gasser. 